\title{
Environmental conditions and physiological state influence estuarine movements of homing sockeye salmon
}

\author{
S. MATTHEW DRENNER, ${ }^{1, *}$ \\ SCOTT G. HINCH, ${ }^{1}$ EDUARDO G. MARTINS, ${ }^{1}$ \\ NATHAN B. FUREY, ${ }^{1}$ TIMOTHY D. CLARK, ${ }^{2}$ \\ STEVEN J. COOKE, ${ }^{3}$ DAVID A. PATTERSON, ${ }^{4}$ \\ DAVID ROBICHAUD, ${ }^{5}$ DAVID W. WELCH, ${ }^{6}$ \\ ANTHONY P. FARRELL ${ }^{7}$ AND \\ RICHARD E. THOMSON ${ }^{8}$ \\ ${ }^{1}$ Department of Forest and Conservation Sciences, University of \\ British Columbia, 2424 Main Mall, Vancouver, BC V6T 124, \\ Canada \\ ${ }^{2}$ Australian Institute of Marine Science PMB 3, Townsville Mail \\ Centre, Townsville, Qld 4810, Australia \\ ${ }^{3}$ Fish Ecology and Conservation Physiology Laboratory, Institute \\ of Environmental Science and Department of Biology, Carleton \\ University, 1125 Colonel By Drive, Ottawa, ON K1S 5B6, \\ Canada \\ ${ }^{4}$ Fisheries and Oceans Canada, Science Branch, Pacific Region, \\ Cooperative Resource Management Institute, School of Resource \\ and Environmental Management, Simon Fraser University, Bur- \\ naby, BC V5A 1S6, Canada \\ ${ }^{5}$ LGL Limited, 9768 Second Street, Sidney, BC V8L 3Y8, \\ Canada \\ ${ }^{6}$ Kintama Research Services Ltd., 10-1850 Northfield Road, \\ Nanaimo, BC V9S 3B3, Canada \\ ${ }^{7}$ Department of Zoology and Faculty of Land and Food Systems, \\ University of British Columbia, 6270 University Boulevard, \\ Vancouver, BC V6T 124, Canada \\ ${ }^{8}$ Fisheries and Oceans Canada, Institute of Ocean Sciences, Sid- \\ ney, BC V8L 4B2, Canada
}

\begin{abstract}
The reproductive migration of anadromous salmonids through estuarine waters is one of the most challenging stages of their life cycle, yet little is known about the environmental and physiological conditions that influence migratory behaviour. We captured, sampled tissues, tagged and released 365 sockeye salmon (Oncorhynchus nerka) homing through inner coastal waters towards the Fraser River, British Columbia, Canada. Biotelemetry was used to assess the behaviour of individual sockeye salmon approaching estuarine waters and at river entry, which were related to both fish
\end{abstract}

*Correspondence. e-mail: smdrenner@gmail.com

Received 1 October 2014

Revised version accepted 28 April 2015

(C) 2015 John Wiley \& Sons Ltd physiological condition at release and to prevailing environmental conditions. Sockeye salmon tended to stay close to the shore, migrated during the day, and movements were related to tide. Sockeye salmon migration rate was linked to wind-induced currents, salinity and an individual's physiological state, but these factors were specific to location and stock. We propose that wind-induced currents exposed sockeye salmon entering the estuary to stronger olfactory cues associated with Fraser River water, which in turn resulted in faster migration rates presumably due to either an increased ability for olfactory navigation and/or advanced reproductive schedule through a neuroendocrine response to olfactory cues. However, once the migration had progressed further into more concentrated freshwater of the river plume, sockeye salmon presumably used wind-induced currents to aid in movements towards the river, which may be associated with energy conservation. Results from this study improve our biological understanding of the movements of Fraser River sockeye salmon and are also broadly relevant to other anadromous salmonids homing in marine environments.

Key words: acoustic tag, diel patterns, homing, migration, oceanography, olfaction, telemetry, windinduced currents

\section{INTRODUCTION}

Anadromous salmonids migrate from feeding grounds in the ocean to natal freshwater sites to spawn. During this reproductive migration, salmon face changing environmental and physiological conditions that can influence migratory behaviour and survival (Healey, 2000; Hinch et al., 2006). Among the various environmental stages of the reproductive migration (i.e., open ocean, coastal, estuarine and riverine), the estuarine stage is perhaps the most challenging due to a high density of predators, variable thermal and osmotic conditions, and anthropogenic factors such as commercial fisheries and pollutants. In addition, homing salmon must gain cues from the environment for navigation (Dittman and Quinn, 1996; Keefer and Caudill, 2014), undergo physiological changes necessary for 
freshwater entry and manage their energy reserves, which are needed to fuel migration, maturation and spawning (Høgåsen, 1998; Hinch et al., 2006; Thorstad et al., 2010).

Despite these diverse and variable year-to-year challenges, the timing of salmon migrations through estuaries and into rivers is remarkably predictable among populations (Groot and Margolis, 1991). This predictability of timing is generally thought to be associated with population-specific adaptations to historic conditions experienced during the freshwater stage of migration such as temperature, flow and other abiotic factors (Hansen and Jonsson, 1991; Taylor, 1991; Hodgson et al., 2006; Jonsson and Jonsson, 2009). All the same, modest variability in timing is observed among individuals within a given population (Stasko, 1975; Cooke et al., 2004; Jonsson et al., 2007), in that a given population may enter the river over a period several weeks, which is known to influence migration success (Hinch et al., 2012). Individual variability in behaviours, such as migration rate and river entry timing, are likely individual responses to different environmental conditions (Hodgson et al., 2006; Jonsson et al., 2007), an individual's energetic state and the time required for individuals to make appropriate physiological adjustments prior to entering the river (Høgåsen, 1998; Hinch et al., 2006). Indeed, studies combining physiological biopsy and telemetry revealed that coastally migrating sockeye salmon (Oncorhynchus nerka) that migrated faster into the river were more reproductively mature, had lower somatic energy reserves and were more osmotically prepared for freshwater (Crossin et al., 2007, 2009; Cooke et al., 2008a).

Environmental conditions in estuarine regions can also influence homing salmon behaviour. Olfactory homing is thought to allow salmon to locate freshwater entry points from estuarine waters (Hasler and Scholz, 1983; Døving et al., 1985; Quinn and Dittman, 1990; Keefer and Caudill, 2014), presumably by salmon gathering cues in surface waters that are influenced by freshwater discharge (Døving and Stabell, 2003) and potentially other environmental conditions such as wind patterns that influence the mixing and transport of these surface waters. For example, the wind-driven spread of olfactory cues was related to migratory route for homing Atlantic salmon (Salmo salar) in a Norwegian fjord (Davidsen et al., 2013). Likewise, salinity in estuaries may also play an important role in river entry timing. In one study, lower estuarine salinities encountered by returning sockeye salmon were associated with earlier river entry (Thomson and Hourston, 2011). Furthermore, diel (Quinn et al.,
1989; Smith and Smith, 1997) and tidal (Stasko, 1975; Levy and Cadenhead, 1995; Aprahamian et al., 1998) patterns of behaviour have been documented for salmon migrating in estuaries, which are likely related to avoiding predators, locating navigational cues, making osmoregulatory adjustments and conserving energy.

Very few studies have related both physiology and environment to marine migration behaviour of anadromous salmon within a single study (Drenner et al., 2012) despite the potential for gaining an understanding of interactions between the environment, physiology and behaviour. Thus, the aim of our study was to build on previous research by relating both environmental conditions and physiological state to the migratory behaviour of homing salmon in estuarine waters and at subsequent river entry. Our specific objectives were to: (i) relate environmental conditions (e.g., wind patterns, discharge and salinity) and individual fish physiological (e.g., reproductive maturity, ionoregulatory state and stress levels as revealed by blood biopsies) and energetic state to migration rate in the estuarine region; (ii) relate the migration pathway used by sockeye salmon in estuarine waters to environmental conditions; and (iii) test for diel patterns and tidal influences on arrival timing in the estuary and at subsequent river entry. This was achieved by taking blood biopsies and implanting acoustic transmitters into homing Fraser River sockeye salmon in marine waters of British Columbia, Canada to follow the passage through strategically located acoustic listening arrays. Fraser River sockeye salmon are comprised of hundreds of genetically distinct populations with different migratory behaviours (Groot and Margolis, 1991), allowing additional examination of populationspecific behaviour within each study objective. Furthermore, Fraser River sockeye salmon are ecologically, economically and culturally valuable species that have experienced variable returns in recent years (Cohen, 2012), and thus a better biological understanding is needed to aid in their management, in particular during their estuarine migration where the majority of commercial fisheries occur.

\section{METHODS}

Study site

The Strait of Georgia (SoG) is a deep inland basin located between mainland British Columbia and Vancouver Island (Fig. 1) that is approximately $200 \mathrm{~km}$ long, $40 \mathrm{~km}$ wide, and has an average and maximum water depth of 155 and $400 \mathrm{~m}$, respectively. The SoG is strongly influenced by freshwater discharge from the 
Figure 1. Map of the study area. 'C' = Chrome Island, 'B' = Buoy 46146, 'PA' = Point Atkinson, 'H' = Hope. Kintama receivers were paired at each location in the lower Fraser River $(n=10)$, whereas all other receiver points represent a single receiver at each location (i.e. 27 OTN receivers, 5 LGL receivers).

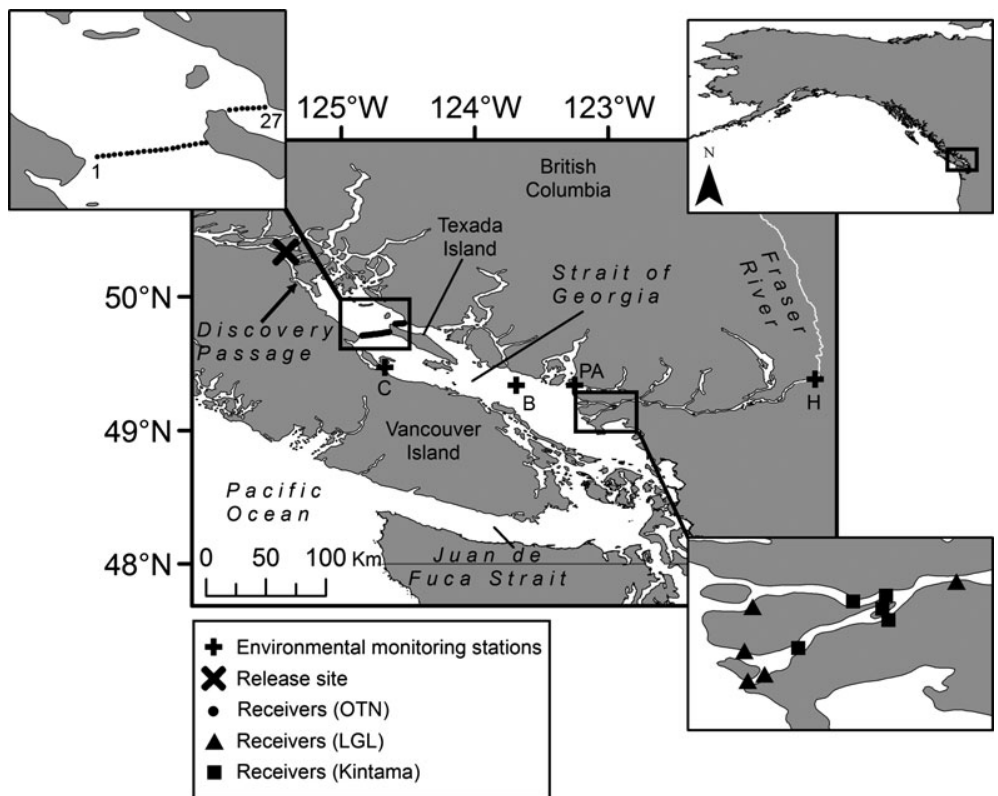

Fraser River. In the summer this warmer, less dense water entering the SoG dilutes the surface layer, causing a strongly stratified interface between the shallow $(<10 \mathrm{~m})$ brackish surface layer and deeper $(>10 \mathrm{~m})$ more saline bottom layer (Thomson, 1981). Tidal currents and wind-generated circulation also strongly influence the environment within the SoG (Thomson, 1981). Currents in the northern SoG maintain a slow $\left(<0.5 \mathrm{~m} \mathrm{~s}^{-1}\right)$ counterclockwise rotation driven mainly by tidal currents and Coriolis effects on the northward-flowing component of the estuarine circulation. Currents in the southern part of the SoG are driven by a combination of winds and river discharge with currents circulating in a clockwise direction. These slower currents $\left(\sim 0.1-0.2 \mathrm{~m} \mathrm{~s}^{-1}\right)$ are also affected by the mixed, mainly semidiurnal tidal currents, which are stronger in the south $\left(\sim 1 \mathrm{~m} \mathrm{~s}^{-1}\right)$ and decrease in strength to the north. Rising tides result in flood currents entering the strait from the south and north (the tides meet in the northern sector of the SoG), while falling tides produce ebb currents that exit the SoG to the south and north.

Hourly water height $(\mathrm{m})$ and mean daily salinity data were compiled from Department of Fisheries and Oceans (DFO) coastal monitoring sites at Point Atkinson and Chrome Island, respectively (Fig. 1). We assigned tidal stage to each hourly water height measurement over the study duration as either flood (the water height at a given hour was greater than the prior hour but less than the following hour), ebb (the water height at a given hour was less than the prior hour but greater than the following hour), low (the water height at a given hour was less than the prior and following hour), or high (the water height at a given hour is greater than the prior and following hour). Hourly near-surface water temperature $\left({ }^{\circ} \mathrm{C}\right)$ and wind data [along-shore wind stress $\left(\mathrm{N} \mathrm{m}^{-2}\right)$, cross-shore wind stress $\left(\mathrm{N} \mathrm{m}^{-2}\right)$ ] were compiled from the Environment Canada Meteorological Buoy 46146 (Fig. 1). Buoy 46146 measured wind variables at $10 \mathrm{~m}$ above the sea surface and water temperature at $3 \mathrm{~m}$ depth. Along-shore wind stress (AlSh) ranged from positive to negative values indicating southeasterly and northwesterly winds, respectively (i.e., parallel to the sockeye salmon migration route) (Fig. 2). Cross-shore wind stress (CrSh) ranged from positive to negative values indicating southwesterly and northeasterly winds, respectively (i.e., perpendicular to the sockeye salmon migration route) (Fig. 2). Fraser River hourly discharge $\left(\mathrm{m}^{3} \mathrm{~s}^{-1}\right)$ measured at Hope was collected from Water Survey of Canada, Environment Canada (Fig. 1).

\section{Fish capture and tagging procedure}

All tagging and sampling were conducted with the approval of the Animal Care Committee of the University of British Columbia, in accordance with the Canadian Council on Animal Care. Adult sockeye salmon $(n=365)$ returning to the Fraser River were captured by commercial troll $(n=340)$ or commercial purse seine $(n=25)$ fisheries in northern Discovery Passage $\sim 215 \mathrm{~km}$ north of the Fraser River mouth (Fig. 1) from 5-18 August- 2010. Individual fish were brought on board the vessel and transferred to a 

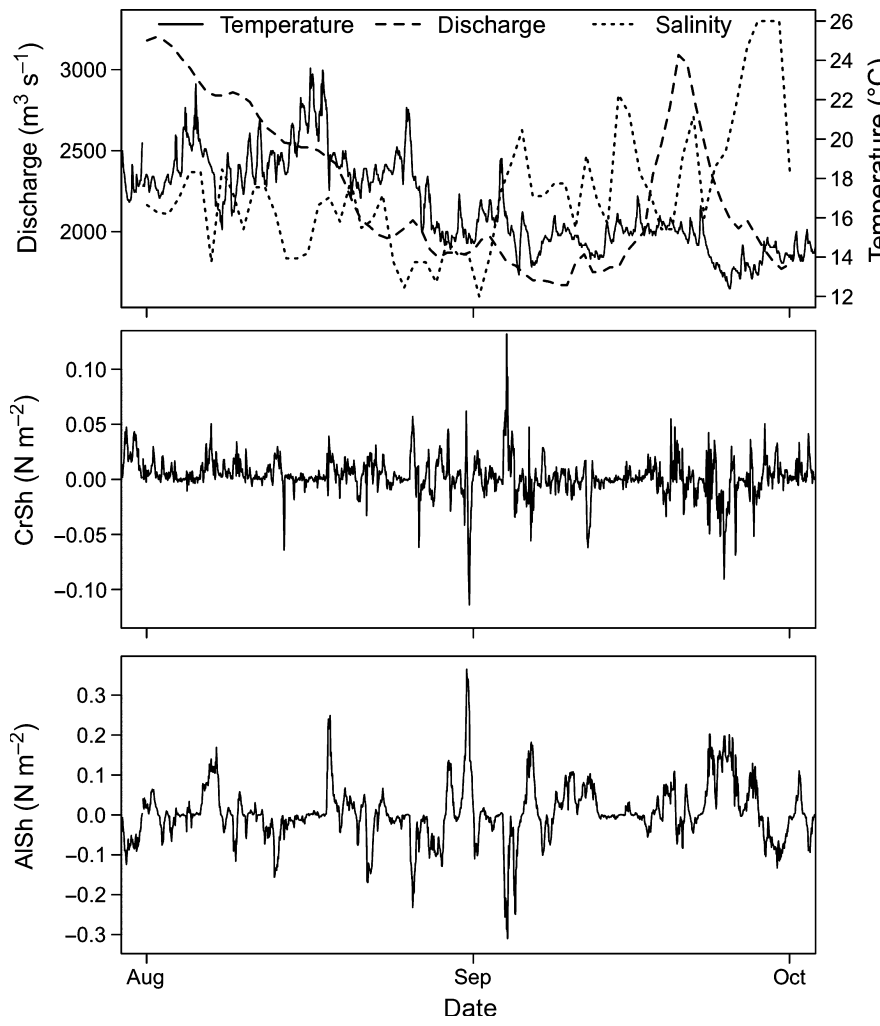

holding tank that was continuously flushed with ambient saltwater for $<15 \mathrm{~min}$ (troll) or $<60 \mathrm{~min}$ (purse seine) prior to undergoing either biopsy or control treatments. The biopsy procedure followed that established for the non-lethal, unanaesthetized handling and sampling of sockeye salmon (Cooke et al., 2005) where individual fish were moved from the holding tank to a foam-padded, $\mathrm{V}$-shaped trough with a constant supply of ambient saltwater. A 3-ml blood sample was taken from the caudal vasculature and stored on ice for up to $8 \mathrm{~h}$ (Clark et al., 2011). A small $(<4 \mathrm{~mm}, 0.03 \mathrm{~g})$ gill tissue sample was taken from the gill filament tips (data not reported herein), and an adipose fin punch $(0.05 \mathrm{~g})$ was taken for DNA stock identification and stored in $95 \%$ ethanol prior to analysis. Fork length (FL) was measured to the nearest $\mathrm{cm}$ and gross somatic energy (GSE) was determined with a hand-held microwave radio emitter (Distell Fish FatMeter FM 692; Distell Inc., Fauldhouse, Scotland, UK; Crossin \& Hinch 2005). Individually coded acoustic transmitters (Vemco V16-3X, 16 mm diameter and $<70 \mathrm{~mm}$ length) were inserted through the mouth into the stomach with a plastic applicator, and a spaghetti tag (Floy Tag \& Mfg. Inc., Seattle, WA, USA) was applied anterior to the dorsal fin through the dorsal musculature to allow visual identification of tagged fish in the case that fish were recaptured by
Figure 2. Environmental variables collected from various monitoring sites from 1 August 2010 to 1 October 2010. fisheries, or for visual identification of fish in spawning areas. A control treatment, which was performed on $80(\sim 22 \%)$ fish, involved only the insertion of an acoustic transmitter, which reduced the extent and time of fish handling $(<3$ versus $<5 \mathrm{~min})$. At least one control fish was tagged after the tagging of 3-8 biopsy fish. Fish were released directly overboard immediately after either treatment. At the end of the workday blood samples were centrifuged, and the blood plasma was transferred into liquid $\mathrm{NO}_{2}$ in preparation for subsequent analysis of plasma concentrations of metabolites (glucose, cortisol and lactate) and sex hormones (testosterone, $17 \beta$-oestradiol), as well as osmolality and ion concentrations $\left(\mathrm{Na}^{+}, \mathrm{Cl}^{-}\right)$.

\section{Characterization of sockeye salmon behaviour}

Individual fish movements were monitored after release using fixed acoustic telemetry arrays [see (Heupel et al., 2006) for details on the technology] that recorded and stored date, time and the individual tag ID when a tagged fish was in proximity to the array. The first point of detection was $\sim 84 \mathrm{~km}$ south of the release site on the Northern Strait of Georgia (NSOG) array, which was a former Pacific Ocean Shelf Tracking (POST) array that is currently an Ocean Tracking Network (OTN) array. The NSOG array consisted of 27 receivers spanning west-to-east 
across the SoG, from Vancouver Island to British Columbia mainland, crossing the northern tip of Texada Island (Fig. 1). This curtain of receivers allowed us to assess migratory pathway of individual fish (i.e., west to east position of where individual fish arrived at the NSOG array), and to test for associations of a migratory pathway with measured environmental and stock-specific variables. The next point of detection was $\sim 131 \mathrm{~km}$ to the southeast of the NSOG array on a series of acoustic receivers that were strategically located in the arms of the Fraser River (Fig. 1), and were used to determine date and time of river entry for individual fish.

The individual fish migration rate was estimated in kilometers per day using the shortest distance between locations. Migration rates were calculated for two sections of migration: (i) from the release site to the NSOG array (i.e., northern SoG region), and (ii) from the NSOG array to Fraser River entry (i.e., central SoG region). We divided sockeye salmon migration through the SoG into two sections because this allowed us to test whether associations between environmental or physiological factors and migration rate changed as migration progressed towards river entry. In addition, we expected that any behavioural effects due to capture, handling and tissue biopsy to be shortlived (Donaldson et al., 2012), and, therefore, only detected in the northern Strait of Georgia given that this section of the migration took on average $\sim 2$ days based on prior estimates (Crossin et al., 2009).

\section{Laboratory assays and physiological data}

DNA analysis of adipose fin clips (Beacham et al., 2004) was used to determine individual fish stock origin. Plasma osmolality, ions $\left(\mathrm{Na}^{+}, \mathrm{Cl}^{-}\right)$, glucose and lactate, were measured using procedures outlined in Farrell et al. (2001) to provide information on osmotic and stress status. Plasma cortisol (for stress), testosterone and $17 \beta$-oestradiol (for reproductive status) were measured using commercial enzyme-linked immunosorbent assay (ELISA) kits (Neogen). Testosterone and $17 \beta$-oestradiol samples were extracted with ethyl ether in accordance with the manufacturer's protocols. Cortisol, testosterone and $17 \beta$-oestradiol samples were all run in duplicate at appropriate dilutions. Additional details on assays are provided in Farrell et al. (2001).

Visual inspection of scatterplots and variance inflation factor (VIF) analysis (Zuur et al., 2010) revealed collinearity among many physiological variables. Therefore, principal component analysis [PCA; according to protocols presented in Field et al. (2012)] was performed on all physiological variables (i.e., cortisol, glucose, lactate, testosterone, $17 \beta$-oestradiol,
$\mathrm{Na}^{+}, \mathrm{Cl}^{-}$and osmolality) to create synthetic variables that represented two or more physiological variables, thereby reducing the number of variables included in our analysis. All physiological variables had a KaiserMayer-Olkin (KMO) score $>0.5$. Based on PCA results, scores were assigned to individual fish for the first and second principle components (PC1 and PC2), which explained $40 \%$ and $23 \%$ of the variation in the data, respectively (see Supporting Information, Table S1). PC1 represented the overall ionic, osmotic and stress condition of fish because lactate, cortisol, osmolality, $\mathrm{Na}^{+}$and $\mathrm{Cl}^{-}$loaded heavily on PC1 (see Supporting Information, Table S1). PC2 represented reproductive maturity because testosterone and $17 \beta$ oestradiol loaded heavily on PC2 (see Supporting Information, Table S1). Glucose was the only variable that loaded heavily on the third PC axis (PC3) (see Supporting Information, Table S1), and, therefore, was included in models as a separate variable rather than including PC3 scores.

\section{Linking environmental data with biotelemetry data}

Environmental variables (temperature, salinity, discharge, AlSh and $\mathrm{CrSh}$ ) were paired with migration rate estimates for individual sockeye salmon within each migration section. In the northern SoG region, the mean of each variable was calculated over 1 day prior to reaching the NSOG array. We selected a time course of 1 day because it represented the approximate minimum number of days it took for sockeye salmon to travel from the release site to the NSOG array, and due to uncertainty of when fish enter the SoG from Discovery Passage, thereby reducing the chance of relating environmental conditions in the SoG to fish that are in Discovery Passage. In addition, 98\% of fish took $>1$ day to reach the NSOG array. Therefore, we felt that a 1-day interval represented the environmental conditions experienced by the greatest number of fish possible. Fish that took $<1$ day $(n=4)$ were not excluded from analyses. In the central SoG region, the mean of each variable was calculated from last detection on the NSOG array to first detection on receivers at river entry.

Visual inspection of scatterplots and VIF analysis revealed collinearity among environmental variables in both migration sections. Specifically, salinity was strongly related to temperature and $\mathrm{CrSh}$ in the northern and central SoG regions, respectively, and river discharge was strongly related to day-of-release (DOR) and day of last NSOG detection (NSOG date) in the northern and central SoG regions, respectively. However, PCA on environmental variables resulted in the poor separation of variables among PC axes. 
Therefore, rather than using PCA as was used on physiological variables, we selected among collinear environmental variables by choosing variables that we believed would have the greatest influence on migration rate based on previous studies. We selected date variables (DOR and NSOG date) in place of discharge for the northern and central SoG regions, respectively, because date could broadly represent environmental conditions and/or the physiological state of fish (Crossin et al., 2009). In addition, salinity was selected in place of temperature and $\mathrm{CrSh}$ for the northern and central SoG regions, respectively, because salinity was associated with sockeye salmon migration timing in a previous study, and, therefore, was of particular interest (Thomson and Hourston, 2011).

\section{Statistical analysis}

Analysis was performed only on sockeye salmon stocks (i.e., aggregates of populations in a spawning region) with large enough sample sizes in the data set to perform rigorous statistical testing [Chilko $(n=46)$, Early Shuswap $(n=53)$, Late Shuswap $(n=130)]$. These sockeye salmon stocks have overlapping migration timing in the estuarine region, but river entry timing can differ among and within stocks (Crossin et al., 2007; Hinch et al., 2012). In particular, since 1995, some portion of the Late Shuswap stock began entering the river earlier than historic norms, resulting in increased en route mortality for these 'early' migrants (Hinch et al., 2012). To further examine this early river entry behavioural phenomenon, we calculated the first and third quartiles of river entry dates for Late Shuswap sockeye salmon, and categorized individuals as 'early-timed' $(N=37)$ or 'normal-timed' $(N=27)$ Late Shuswap fish if they entered the river before the first quartile or after the third quartile, respectively. While this selective approach excluded 66 individuals, it ensured that the fish assigned to either group were representative of the two river entry behaviours.

Relationships between the individual fish migratory pathway at the NSOG array (i.e., NSOG receivers divided into four sections grouped from west to east) and predictor variables (AlSh, CrSh, DOR and stockgroup) were evaluated using multinomial modelling and model selection via Akaike's information criterion corrected for small sample sizes $\left(\mathrm{AIC}_{\mathrm{c}}\right)$ (Burnham and Anderson, 2002). Multinomial modelling and model comparison based on $\triangle \mathrm{AIC}_{\mathrm{c}}$ and $\mathrm{AIC}_{\mathrm{c}}$ weights $\left(w_{i}\right)$ was performed using $\mathrm{R}$ packages (R Core Development Team, 2012) 'nnet' (Venables and Ripley, 2002) and 'MuMIn' (Barton, 2013), respectively. Model averaging was applied to a 95\% confidence set of models (all models with cumulatively summed weights $\geq 0.95)$ to incorporate model selection uncertainty (Burnham and Anderson, 2002). Models were fitted with standardized continuous predictor variables (Gelman, 2008), which allowed us to estimate and directly compare effect sizes among predictor variables (Schielzeth, 2010). Variables were selected as being associated with the response variable when the effect size was statistically different from zero (i.e., when the 95\% confidence intervals for estimates of effect size did not intersect zero).

Differences in migratory pathway used by sockeye salmon along four grouped sections of the NSOG array (e.g. NSOG pathway) were tested with a chi-square test weighted for the number of receivers included in each of four possible NSOG pathways. In addition, chi-square tests were used to test whether sockeye salmon arrived at the NSOG array or entered the Fraser River at day or night (based on civil twilight) weighted for the number of hours in each diel state, and at different tidal stages (e.g., flood, ebb, low and high) weighted for the number of hours in each tidal stage over the study. If significant differences were found among NSOG pathways or tidal stages, post hoc weighted chi-square tests were made for all pair-wise comparisons, and Bonferroni's corrections were used to adjust $P$-values to account for multiple tests.

Relationships between migration rate and predictor variables were examined using linear regression, $\mathrm{AIC}_{\mathrm{c}}$ model selection and effect size as described above for NSOG migratory pathway analysis. Migration rate data were analysed in two models sets run separately for each section of migration (i.e., northern and central SoG regions). The first set of models (termed 'environmental') took advantage of the full data set ( $n=163$ and $n=147$ for the northern and central SoG regions, respectively), the primary focus being to assess whether environmental variables influenced migration rate. Additional predictor variables [treatment (biopsy or control), capture method (purse seine or troll), FL and date variables (DOR or NSOG date)] were also included in the 'environmental' model because these variables could potentially influence migration rate, and, therefore, we wanted to account for them to properly estimate the effects of environmental variables. Specific predictor variables included in the 'environmental' models examining migration rate in the northern SoG region were salinity, AlSh, CrSh, treatment (biopsy or control), capture method (purse seine or troll), FL and DOR. The same predictor variables were included in the 'environmental' model examining migration rate in the central SoG region with the exception of temperature in place of $\mathrm{CrSh}$ and NSOG date in place of DOR. 
To assess whether physiological variables influenced migration rate, a second set of models (termed 'physiological') was fitted to data from a subset of fish $(n=99$ and $n=90$ for the northern and central SoG regions, respectively) for which physiological data were available (i.e., biopsied fish). Predictor variables included in the 'physiological' models were physiological condition (PC1 scores), reproductive maturity (PC2 scores), glucose, GSE and sex [assigned based on reproductive hormone concentrations (Cooke et al., 2006)]. In addition to physiological variables, any variables selected based on effect size from the 'environmental' models were also included in the 'physiological' model because the previous model indicated they were important in explaining migration rate.

We also included a variable representing stockgroup (i.e., Chilko, Early Shuswap, 'early-timed' Late Shuswap and 'normal-timed' Late Shuswap) and interactions between stock-group and all other predictor variables in both 'environmental' and 'physiological' models. Stock-group was included in all models for the central SoG region, and was, therefore, not subject to model selection, because of prior known differences in migration behaviour among stock-groups in the estuary (Groot and Margolis, 1991; Cooke et al., 2004).

Diagnostics for heteroscedasticity, normality and independence of residuals were visually inspected and revealed a violation of heteroscedasticity in migration rate models for the central SoG region. Therefore, we used generalized least squares (GLS) modelling in the central SoG region, and variance structure selection was applied to residuals of the stock-group that was identified as contributing to heteroscedasticity (Zuur et al., 2009). Model predictions for a range of values of a given variable present in the $95 \%$ confidence set of models was done while using the median value for the other continuous variables and selecting a level of a categorical variable that we would expect to represent better a freely migrating fish (e.g., vigorous fish rather than lethargic or moderately impaired fish).

\section{RESULTS}

\section{Northern SoG region}

Among sockeye salmon from the targeted stockgroups, 46 Chilko, 53 Early Shuswap, 37 'early-timed' and 27 'normal-timed' Late Shuswap fish were detected on the NSOG array. Compared with 'normal-timed' Late Shuswap fish, Chilko, Early Shuswap and 'early-timed' Late Shuswap fish were tagged/ released and reached the NSOG array at earlier dates (Fig. 3). Sockeye salmon migration rate in the northern SoG region was similar among stock-groups
(Fig. 4). The mean, minimum and maximum migration rate for all stocks combined in the northern SoG region was 42.5, 10.1 and $93.0 \mathrm{~km}$ per day, respectively.

Sockeye salmon displayed preferences for migratory pathways and near-shore migration upon arrival at the NSOG array (grouped into four segments) $\left(\chi^{2}\right.$ test $=29.09$, d.f. $=3, P<0.001) \quad($ Fig. 5, Table 1). Most sockeye salmon migrated down the west side of the SoG along Vancouver Island (NSOG pathway 1, receiver numbers 1-6) and the east side of the SoG on

Figure 3. Boxplots of dates when sockeye salmon stocks were captured and released (upper), detected on the NSOG detection array (middle), and entered the river (lower). Data are presented for Chilko, Early Shuswap (ES), 'early-timed' Late Shuswap (earlyLS), and 'normal-timed' Late Shuswap (normLS) stock-groups. Solid bold horizontal lines within boxes represent the median, box limits represent the interquartile range (IQR), and whiskers represent $1.5 \times$ the IQR. Open circles represent outliers. Outliers were defined as outside $1.5 \times$ the IQR above the upper quartile and below the lower quartile.
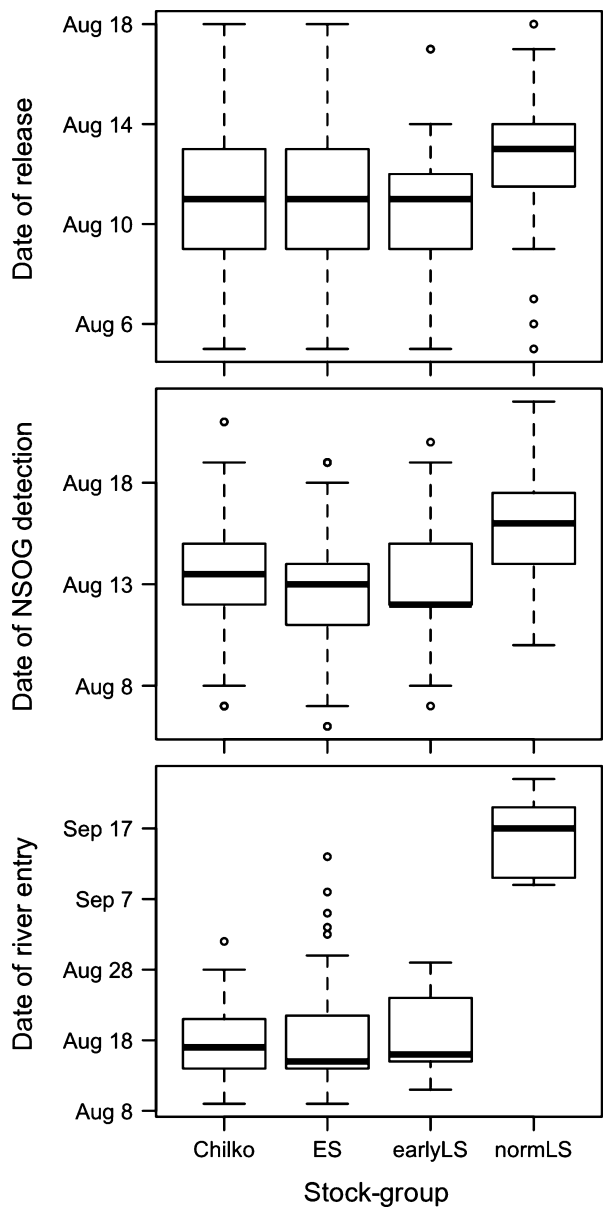
Figure 4. Boxplots of migration rates for Chilko, Early Shuswap (ES), 'early-timed' Late Shuswap (earlyLS) and 'normal-timed' Late Shuswap (normLS) stock-groups. Migration rates are shown for each stock-group in the northern (white) and central (grey) SoG regions. Solid bold horizontal lines within boxes represent the median, box limits represent the interquartile range (IQR) and whiskers represent $1.5 \times$ the IQR. Open circles represent outliers. Outliers were defined as outside $1.5 \times$ the IQR above the upper quartile and below the lower quartile.
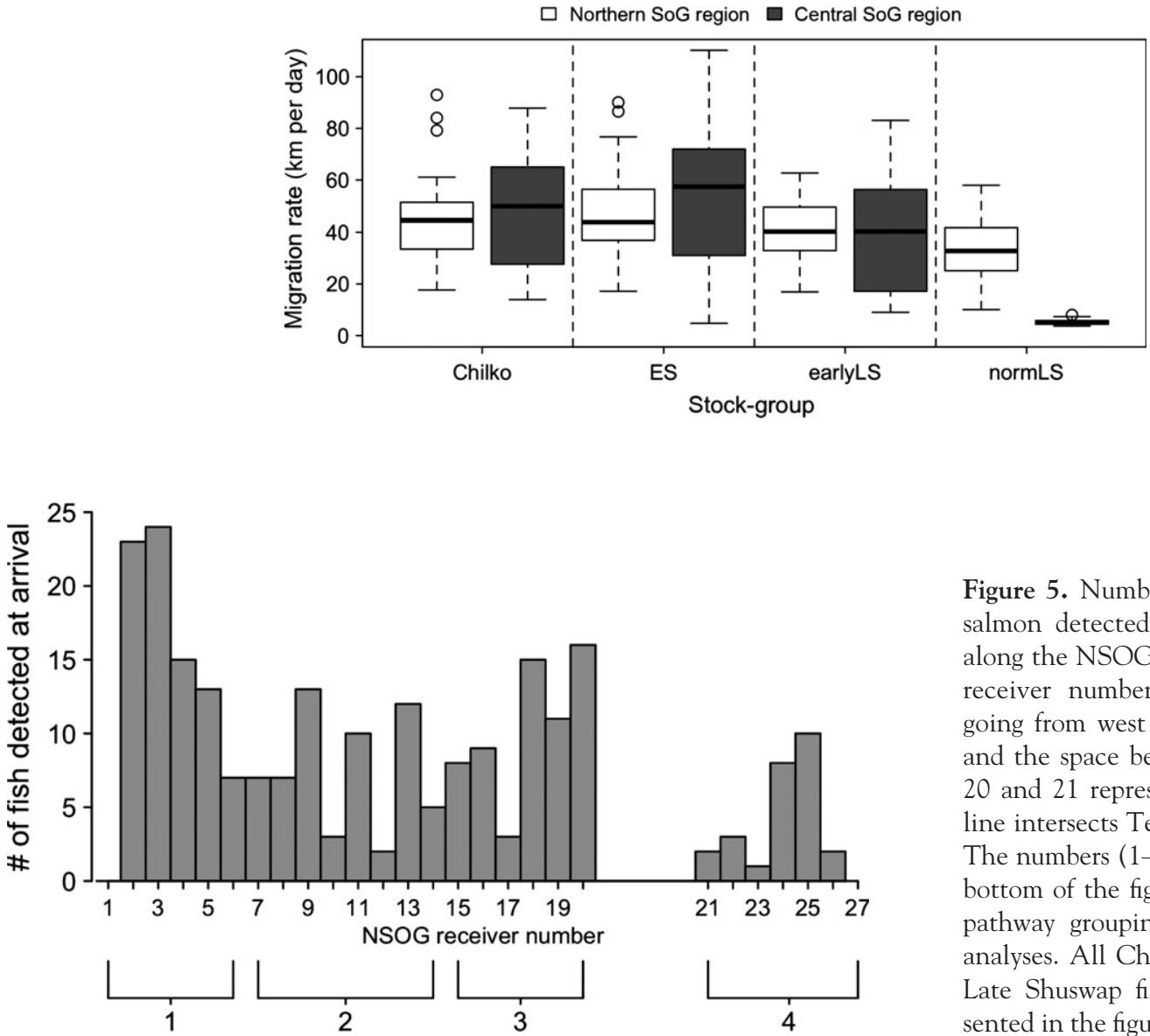

Figure 5. Number of individual sockeye salmon detected at arrival on receivers along the NSOG detection array. NSOG receiver numbers range from 1 to 27 going from west to east across the SoG, and the space between receiver numbers 20 and 21 represents where the receiver line intersects Texada Island (see Fig. 1). The numbers (1-4) below brackets at the bottom of the figure indicate the NSOG pathway groupings of receivers used in analyses. All Chilko, Early Shuswap and Late Shuswap fish $(n=229)$ are represented in the figure.

the west side of Texada Island (NSOG pathway 3, receiver numbers 15-20) (Fig. 5, Table 1) with no significant difference between these two pathways $\left(\chi^{2}\right.$ test 0.77 d.f. $=1, P=0.38)$. Relatively fewer sockeye salmon used the strait between Texada Island and British Columbia mainland (NSOG pathway 4, receiver numbers 21-27) compared with the NSOG pathway $1\left(\chi^{2}\right.$ test $=22.75$, d.f. $\left.=1, P<0.001\right)$ and the NSOG pathway $3\left(\chi^{2}\right.$ test $=15.22, \quad$ d.f. $=1$, $P<0.001$ ) (Fig. 5). In addition, sockeye salmon used NSOG pathway 1 more than the middle of the NSOG (NSOG pathway 2 , receiver numbers 7-14) $\left(\chi^{2}\right.$ test $=12.14$, d.f. $=1, P=0.003)$ (Fig. 5). No other significant differences were found among NSOG migratory pathways. In addition, none of the predictor variables (i.e., stock-group, DOR, CrSh and AlSh) were associated with the NSOG pathway used by sockeye salmon and, therefore, no further information is presented for this model.

Significantly more sockeye salmon reached the NSOG array during the day than at night $\left(\chi^{2}\right.$ test $=26.73$, d.f. $=1, P<0.001)$ and at different tide stages $\left(\chi^{2}\right.$ test $=13.50$, d.f. $\left.=3, P=0.004\right)($ Table 2$)$. Post hoc comparisons showed that sockeye salmon reached the NSOG array more frequently on ebb tides compared to flood $\left(\chi^{2}\right.$ test $=13.46, \quad$ d.f. $=1$, $P=0.001)$, but there were no other significant differences among tide stages.

Sockeye salmon migration rate in the northern SoG region was associated with AlSh, treatment, salinity, stock, and the interaction of stock and salinity based on effect size for the 'environmental' model (Fig. 6). Predictions for the relationship between AlSh and sockeye salmon migration rate showed a 
Table 1. Comparisons of the number of sockeye salmon detected upon arrival at each NSOG position. Numbers in parentheses indicate percentages.

\begin{tabular}{lcl}
\hline $\begin{array}{l}\text { NSOG } \\
\text { position }\end{array}$ & $\begin{array}{c}\text { NSOG receiver } \\
\text { numbers }\end{array}$ & $\begin{array}{c}\text { Number of sockeye salmon } \\
\text { detected at arrival }\end{array}$ \\
\hline 1 & $1-6$ & $57(35)$ \\
2 & $7-14$ & $37(23)$ \\
3 & $15-20$ & $48(30)$ \\
4 & $21-27$ & $21(13)$ \\
\hline
\end{tabular}

Table 2. Comparisons of the number of sockeye salmon reaching the NSOG detection array or entering the Fraser River during day or night and at different tidal stages. Numbers in parentheses indicate percentages.

\begin{tabular}{lcc}
\hline Location & Condition & Number \\
\hline NSOG array & day & $132(81)$ \\
night & $31(19)$ \\
flood & $48(29)$ \\
high & $15(9)$ \\
ebb & $89(55)$ \\
low & $11(7)$ \\
Fraser River entry & day & $116(79)$ \\
& night & $31(21)$ \\
& flood & $51(35)$ \\
high & $4(3)$ \\
ebb & $68(46)$ \\
low & $24(16)$ \\
\hline
\end{tabular}

positive relationship, indicating that under positive values of AlSh (i.e., stronger southeasterly winds) sockeye salmon migrated faster to the NSOG array (Fig. 7, upper left panel). Model predictions also indicated that sockeye salmon that experienced higher salinity migrated faster than sockeye salmon that experienced lower salinity, but this relationship was not as strong for 'normal-timed' Late Shuswap fish (Fig. 7, upper middle panel), which were the latest of the fish groups tested. Lastly, sockeye salmon that were biopsied for blood and gill tissue migrated $\sim 6.5 \mathrm{~km}$ per day slower than sockeye salmon from the 'control' group (i.e., about a 6-h delay). The top-ranked 'environmental' model for the northern SoG region explained a low amount of the variability in the data (adjusted$\left.\mathrm{R}^{2}=0.20\right)($ Table 3$)$.

The 'physiological' model for the northern SoG region indicated an effect of AlSh and the interaction between glucose and stock on migration rate (Fig. 6). Model predictions indicated that Chilko and Early Shuswap fish with higher plasma glucose concentrations migrated faster to the NSOG array, whereas both 'early-timed' and 'normal-timed' Late Shuswap fish with higher levels of glucose migrated slower to the NSOG array (Fig. 7, upper right panel). However, glucose, stock, or the interaction of glucose and stock were not present in all top-ranked models (Table 3), which suggests uncertainty with regards to its overall importance as a predictor of sockeye salmon migration rate. In addition, salinity was no longer present in any top-ranked models once it was incorporated into 'physiological' models that had reduced samples sizes (Table 3). The top ranked 'physiological' model for the northern SoG region explained a similar amount of the variability in the data (adjusted- $\mathrm{R}^{2}=0.21$ ) as the top ranked 'environmental' model, and both top ranked models contained the variables AlSh and stock, indicating these variables account for the largest amount of the variability in the data (Table 3 ).

\section{Central SoG region}

Of the 36 Chilko, 47 Early Shuswap, 37 'early-timed' and 27 'normal-timed' Late Shuswap fish detected on receivers in the Fraser River, the 'normal-timed' Late Shuswap fish migrated slower in the central SoG region (Fig. 4). Additionally, migration rates for 'normal-timed' Late Shuswap fish were slower in the central SoG region compared to the northern SoG region (Fig. 4).

River entry occurred more during the day than at night $\left(\chi^{2}\right.$ test $=19.90$, d.f. $\left.=1, P<0.001\right)$, and there was a significant difference in river entry among tide stages $\left(\chi^{2}\right.$ test $=24.60$, d.f. $\left.=3, P<0.001\right)($ Table 2$)$. Post hoc comparisons revealed that sockeye salmon entered the river less during low tide compared to ebb tide $\left(\chi^{2}\right.$ test $=10.71$, d.f. $\left.=1, P=0.006\right)$ or flood $\left(\chi^{2}\right.$ test $=18.41$, d.f. $=1, P<0.001)$, but there were no other differences between tidal stages during river entry.

Sockeye salmon migration rate in the central SoG region was associated with AlSh, stock and the interaction between stock and NSOG last detection date based on the 'environmental' model selection (Fig. 8). Predictions for the relationship between AlSh and sockeye salmon migration rate in the central SoG region were opposite from predictions in the northern SoG region and showed a negative relationship. This indicates that under negative values of AlSh (i.e., stronger northwesterly winds) sockeye salmon migrated faster from the NSOG array to the Fraser River (Fig. 7, lower left panel). Model predictions also indicated that Chilko and Early Shuswap fish that reached the NSOG array at earlier dates migrated faster into the Fraser River (Fig. 7, lower right panel). In contrast, migration rates for both 'early-timed' and 'normal-timed' Late Shuswap fish were not strongly related to the date they 
Figure 6. Model averaged scaled parameter estimates (circles) with 95\% confidence intervals (lines) for migration rate in the northern SoG region from two models. The 'environmental' model (left) used the full data set $(n=163)$ with the primary goal of assessing whether environmental variables influenced migration rate, but also included additional variables [i.e., FL (fork length), DOR (day-of-release), capture method (troll or purse seine) and treatment (biopsy or control)] that had data available for the full data set. The 'physiological' model (right) used data from a subset of fish $(n=99)$ for which physiological data were available to assess whether physiological variables influenced migration rate, but also included any variables selected based on effect size from the 'environmental' model. An asterisk preceding the variable names signifies that the 95\% confidence intervals for the scaled parameter estimate did not intersect zero. Additional abbreviations are presented as ES (Early Shuswap), earlyLS ('early-timed' Late Shuswap), normLS ('normal-timed' Late Shuswap), CrSh (cross-shore wind stress), AlSh (along-shore wind stress), GSE (gross somatic energy), PC1 (first principle component; represented overall fish condition), and PC2 (second principle component; represented reproductive maturity).

\section{Northern SoG region/environmental}

Northern SoG region/physiological

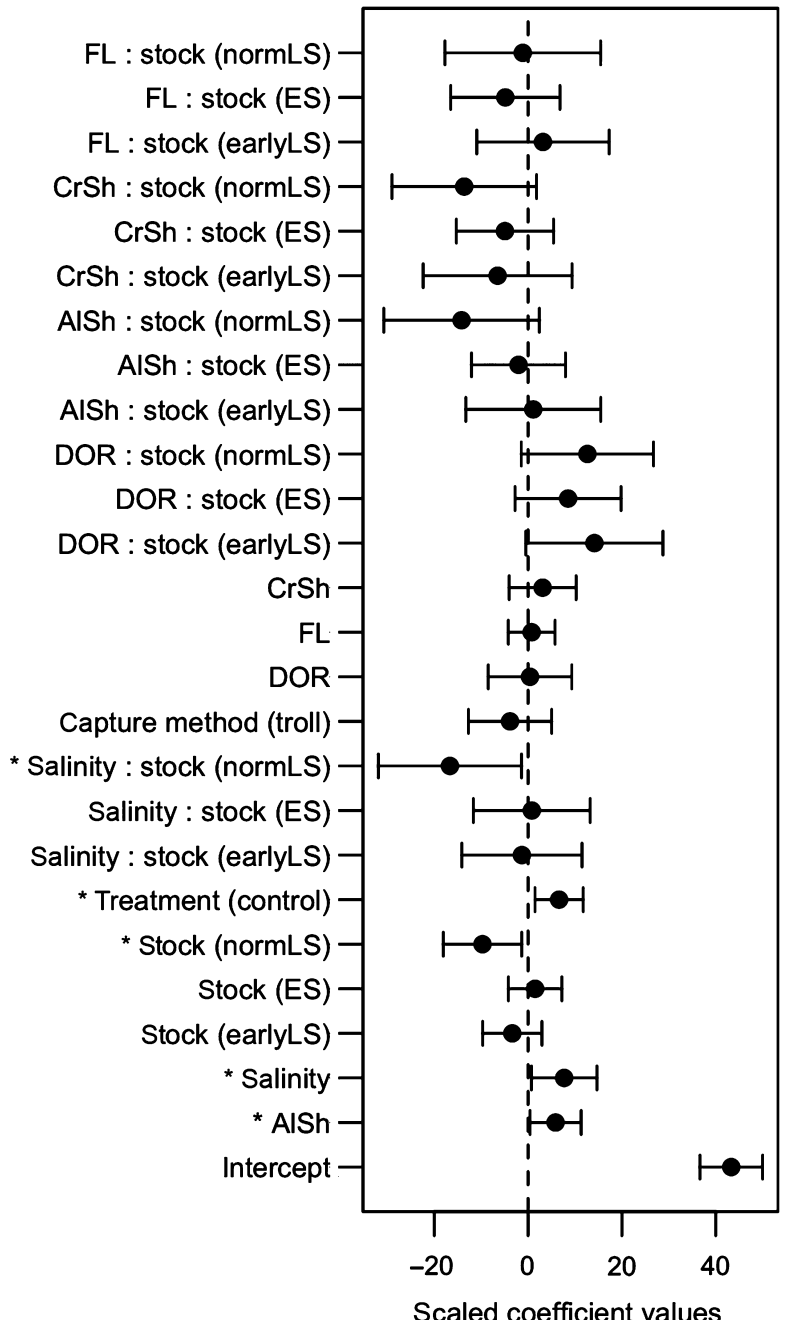

were last detected on the NSOG array, and 'normaltimed' Late Shuswap fish migrated much slower compared to all other stocks (Fig. 7).

Once variables selected from the 'environmental' model were incorporated into the 'physiological' model for the central SoG region, none of the physiological variables were selected based on effect size

(Fig. 8), although PC2 was present in all top-ranked 'physiological' models (Table 3). The top-ranked model that included both AlSh and the interaction of stock with NSOG date explained an exceptionally high amount of the variation in the data (adjusted$\mathrm{R}^{2}=0.91$ ) (Table 3 ) that could not be solely attributed to differences among stock-groups because the 
Figure 7. Model averaged predictions for migration rate based on variables selected as being associated with sockeye salmon migration rate in the northern (A) and central (B) SoG regions. The upper $x$-axis is the actual value of the variable, and the lower $x$-axis is the standardized variable (in SD units). Model predictions are presented for the Chilko, Early Shuswap (ES), 'early-timed' Late Shuswap (earlyLS), and 'normal-timed' Late Shuswap (normLS) stock-groups. Abbreviations are presented as AlSh (along-shore wind stress) and NSOG date (day of last NSOG detection).
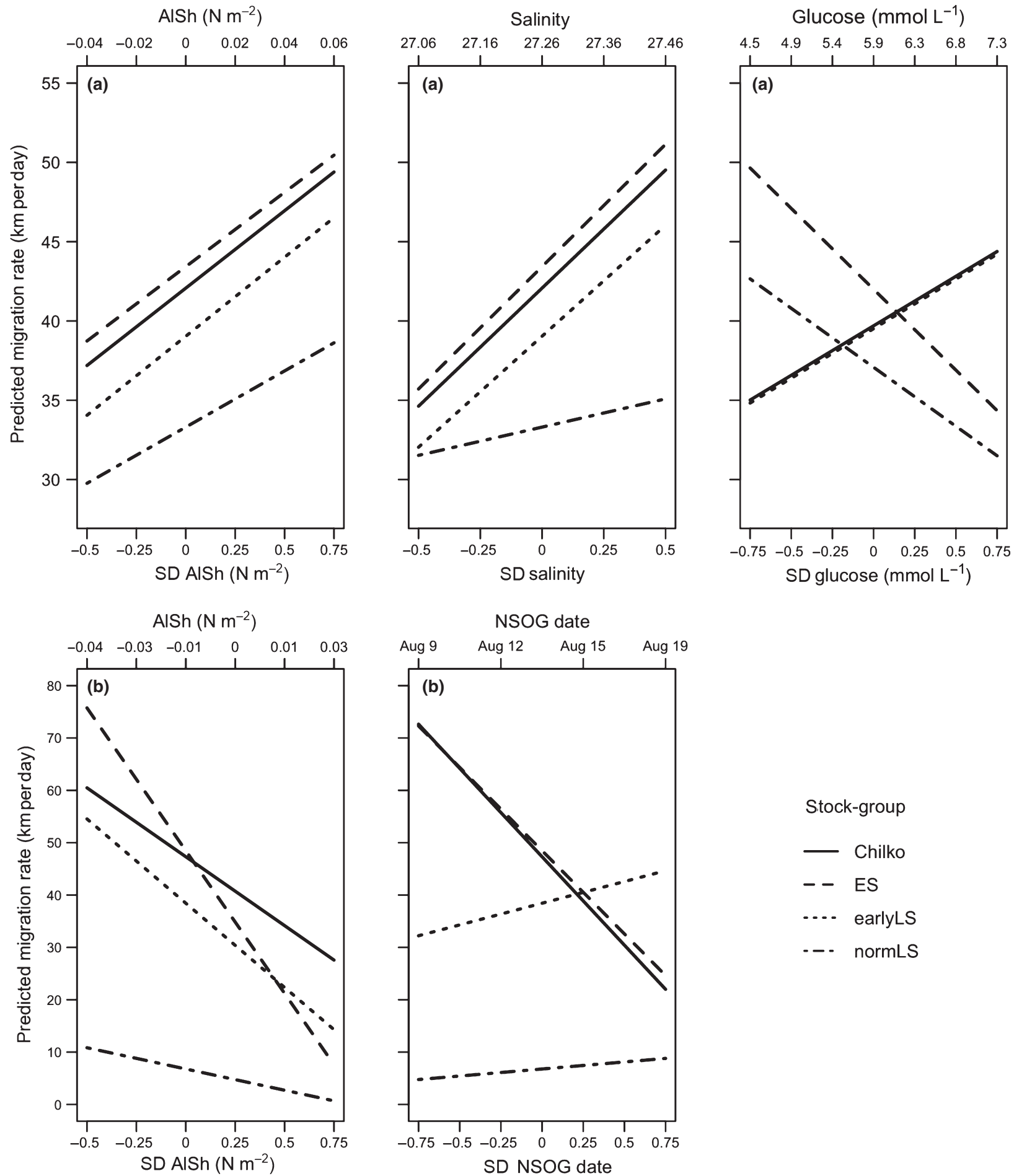

Stock-group

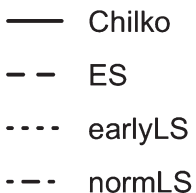


Table 3. Model selection results based on $\mathrm{AIC}_{\mathrm{c}}$ showing top models $\left(\Delta \mathrm{AIC}_{\mathrm{c}}<2\right)$, to a maximum of five models, from a $95 \%$ confidence set of models. Models results are shown for 'environmental' and 'physiological' models in the northern and central SoG regions. The 'environmental' model used the full data set ( $n=163$ and $n=147$ for the northern and central SoG regions, respectively) with the primary goal of assessing whether environmental variables influenced migration rate, but also included additional variables [i.e., FL (fork length), DOR (day-of-release), NSOG date (day of last NSOG detection), capture method (troll or purse seine), treatment (biopsy or control), and stock] that had data available for the full data set. The 'physiological' model used data from a subset of fish ( $n=99$ and $n=90$ for the northern and central SoG regions, respectively) for which physiological data was available to assess whether physiological variables influenced migration rate, but also included any variables selected based on effect size from the 'environmental' model. Stock was included in all models for the central SoG region due to prior known differences, and therefore was not subject to model selection. Additional abbreviations are presented as AlSh (along-shore wind stress) and PC2 (second principle component; represented reproductive maturity).

\begin{tabular}{|c|c|c|c|c|c|}
\hline $\begin{array}{l}\text { Migration section/ } \\
\text { model step }\end{array}$ & Model & $\mathrm{K}$ & $\Delta \mathrm{AIC}_{\mathrm{c}}$ & $W_{\mathrm{i}}$ & Adjusted- $\mathrm{R}^{2}$ \\
\hline \multicolumn{6}{|c|}{ Northern SoG Region } \\
\hline \multirow{5}{*}{ Environmental } & AlSh, salinity, treatment, stock & 4 & 0.00 & 0.06 & \multirow[t]{5}{*}{0.20} \\
\hline & AlSh, treatment, stock $\times$ salinity & 5 & 0.81 & 0.04 & \\
\hline & AlSh, salinity, treatment, stock, capture method & 5 & 0.92 & 0.04 & \\
\hline & AlSh, salinity, treatment, stock, release date & 5 & 1.58 & 0.03 & \\
\hline & AlSh, treatment, stock $\times$ salinity, release date & 6 & 1.66 & 0.03 & \\
\hline \multirow[t]{5}{*}{ Physiological } & AlSh, stock $\times$ glucose & 4 & 0.00 & 0.04 & \multirow[t]{5}{*}{0.21} \\
\hline & AlSh, stock & 2 & 0.38 & 0.03 & \\
\hline & AlSh, stock $\times$ glucose, sex & 5 & 0.56 & 0.03 & \\
\hline & AlSh & 1 & 0.76 & 0.02 & \\
\hline & AlSh, glucose & 2 & 1.09 & 0.02 & \\
\hline \multicolumn{6}{|c|}{ Central SoG Region } \\
\hline \multirow[t]{2}{*}{ Environmental } & stock $\times$ NSOG date, stock $\times$ temperature, salinity, stock $\times$ AlSh & 8 & 0.00 & 0.15 & \multirow[t]{2}{*}{0.91} \\
\hline & NSOG date, temperature, salinity, stock $\times$ AlSh & 6 & 0.17 & 0.13 & \\
\hline \multirow[t]{5}{*}{ Physiological } & stock $\times$ NSOG date, $\mathrm{PC2}$, AlSh, sex & 6 & 0.00 & 0.11 & \multirow[t]{5}{*}{0.91} \\
\hline & stock $\times$ NSOG date, $\mathrm{PC} 2$, AlSh & 5 & 0.01 & 0.11 & \\
\hline & stock, NSOG date, PC2, AlSh, sex & 5 & 0.46 & 0.08 & \\
\hline & stock, NSOG date, PC2, AlSh & 4 & 0.67 & 0.08 & \\
\hline & stock $\times$ NSOG date, $\mathrm{PC} 2$, AlSh, glucose & 6 & 1.33 & 0.06 & \\
\hline
\end{tabular}

adjusted- $\mathrm{R}^{2}$ value decreased to only 0.74 when stockgroup was removed from the model.

\section{DISCUSSION}

The present study, combined telemetry, tissue biopsy and environmental monitoring to examine environmental and physiological influences on homing sockeye salmon behaviour in coastal and estuarine waters. Our estimates for migration rate in the SoG (mean $=37 \mathrm{~km}$ per day, $\mathrm{SD} \pm 22 \mathrm{~km}$ per day) were within ranges reported in previous studies on homing sockeye salmon in estuaries (Madison et al., 1972; Stasko et al., 1976; Quinn, 1988; Quinn et al., 1989; Crossin et al., 2007). As anticipated, there was variability in migration timing and rate among stock-groups in our study that were mostly attributed to differences between the 'normal-timed' Late Shuswap stock-group and the other stocks. 'Normal-timed' Late Shuswap fish had much slower migration rates in the central SoG region compared to all other stock-groups, which reflects the previously known tendency of this particular stock to mill in the estuary prior to entering the river (Hinch et al., 2012). It was first believed that the key trait separating 'early-timed' and 'normal-timed' Late Shuswap fish was that the 'early-timed' Late Shuswap fish did not mill in the estuary resulting in earlier river entry for this segment of the Late Shuswap stock. Thus, the river entry date has been the metric used to categorize Late Shuswap fish as either 'early-timed' or 'normal-timed' (Cooke et al., 2004) as was done in the present study. However, of particular note, the 'early-timed' Late Shuswap fish were consistently earlier migrants than the 'normal-timed' Late Shuswap fish throughout the area examined in our study. This has been noted by other studies (Hinch et al., 2012) and indicates the 'early entry' behavioural phenomena of a segment of the Late Shuswap stock has already commenced 
Figure 8. Model averaged scaled parameter estimates (circles) with 95\% confidence intervals (lines) for sockeye salmon migration rate in the central SoG region from two models. The 'environmental' model (left) used the full data set $(n=147)$ with the primary goal of assessing whether environmental variables influenced sockeye salmon migration rate, but also included additional variables [i.e., FL (fork length), NSOG date (day of last NSOG detection), capture method (troll or purse seine) and treatment (biopsy or control)] that had data available for the full data set. The 'physiological' model (right) used data from a subset of fish $(n=90)$ for which physiological data were available to assess whether physiological variables influenced migration rate, but also included any variables selected based on effect size from the 'environmental' model. An asterisk preceding a variable name signifies that the $95 \%$ confidence intervals for the scaled parameter estimate did not intersect zero. Additional abbreviations are presented as ES (Early Shuswap), earlyLS ('early-timed' Late Shuswap), normLS ('normal-timed' Late Shuswap), CrSh (cross-shore wind stress), AlSh (along-shore wind stress), GSE (gross somatic energy), PC1 (first principle component; represented overall fish condition), and PC2 (second principle component; represented reproductive maturity).

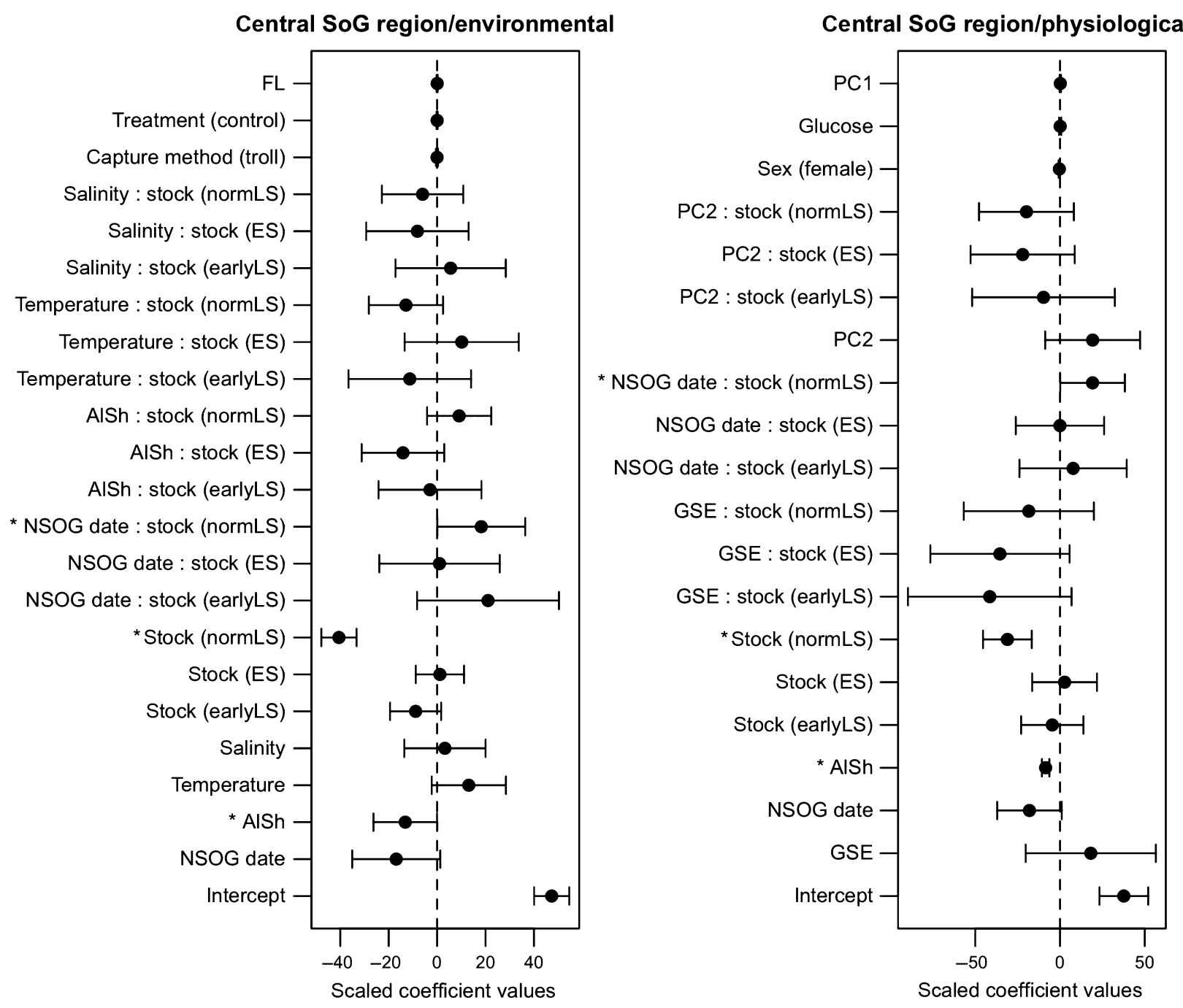

by the time these fish arrive in the inner coastal and estuarine areas.

While migrating through estuaries, homing salmon are thought to rely on a number of cues to aid in orientation and navigation (Keefer and Caudill, 2014). For example, both homing Atlantic and Pacific salmon (Oncorhynchus spp.) have been observed following coastlines during their estuarine migration (Quinn

et al., 1989; Davidsen et al., 2013). In our study, sockeye salmon tended to follow close to the coastlines against Vancouver Island and the west side of Texada Island. Currents in the northern SoG maintain a slow counterclockwise rotation during the time of year sockeye salmon are migrating in the estuarine region (Thomson, 1981), and some sockeye salmon may use these currents that flow southward along Vancouver 
Island to swim in an energetically efficient manner. Alternatively, following coastlines (or using shallower depths associated with coastlines) may assist in navigation through complex coastal systems. Interestingly, outmigrating sockeye salmon smolts tend to use the strait on the east side of the SoG between Texada Island and the BC mainland (Welch et al., 2009), providing further evidence of the importance of coastlines in Pacific salmon migration across multiple life stages.

Many studies on homing salmon have examined the use of tides and diel patterns [reviewed in (Drenner et al., 2012)] without reaching a consensus on the direction of relationships and patterns (Smith and Smith, 1997). Our study indicated that sockeye salmon in the estuary and at river entry moved more frequently during the day, which is similar to other studies on sockeye salmon that noted faster swimming in estuaries during the day (Madison et al., 1972; Quinn, 1988; Wilson et al., 2014). All fish in our study were tagged and released during the day, which could influence arrival timing on the NSOG array that was a mean of $\sim 2.4$ days travel time from the release site. Although there was a large amount of variability among fish in the number of days it took to reach the NSOG line (i.e., minimum $=0.7$ days and maximum $=8.6$ days), $\sim 40 \%$ of fish reached the NSOG array between 1 and 2 days after release, and therefore, release timing may have affected diurnal patterns on the NSOG line. Diurnal movements could be related to gathering visual cues during the daytime, such as polarized light, that supplements other navigation or orientation cues.

Sockeye salmon in our study reached the NSOG array less frequently during flood tides, compared to ebb, low or high tides, and entered the Fraser River less frequently during low tides compared to flood or ebb. Variable use of tide by sockeye salmon in the SoG has been noted in earlier studies (Wilson et al., 2014). Interestingly, Levy and Cadenhead (1995) found that sockeye salmon migrate more frequently into the Fraser River on flood tides, potentially as a strategy for energy conservation. Although our study did not detect a similar tidal pattern associated with river entry, the sockeye salmon stock from Levy and Cadenhead (1995) have a much longer in-river migration distance to spawning grounds compared to the sockeye salmon from our study, and therefore, energy conservation may be more important for that particular stock. Overall, the factors influencing diel patterns and tidal use of homing salmon in estuaries are complex and may be species, stock and location specific.

One of the predominant mechanisms salmon are thought to use in estuaries for orientation and navigation is olfactory homing (Hasler and Scholz, 1983; Quinn and Dittman, 1990; Keefer and Caudill, 2014), where fish gather olfactory cues that are emitted into estuaries from freshwater entry points. The presence, concentration and spatial distribution of olfactory cues in estuaries are dependent on environmental forces such as river discharge, tides and windinduced currents. In the SoG, oceanography is heavily influenced by wind-induced currents (Thomson, 1981), and our study found that stronger southeasterly winds were associated with faster migration rates for sockeye salmon migrating in the northern SoG region (i.e., from the release site to the NSOG array). Stronger southeasterly winds over the SoG would result in stronger estuarine outflow in the northern sector of the strait towards the ocean. This outflow would push fresh water exiting the Fraser River northward along the SoG in the upper $50-70 \mathrm{~m}$ of the water column (Thomson, 1994), which corresponds to the depths homing sockeye salmon utilize in estuarine waters (Quinn et al., 1989; Wilson et al., 2014). Therefore, under stronger southeasterly winds, sockeye salmon entering the northern SoG from the Discovery Passage would encounter a stronger Fraser River signal, which could result in increased migration rates under a few possible scenarios described below.

One possibility is that stronger southeasterly winds established a gradient of olfactory cues that sockeye salmon followed, thereby increasing their homing precision and thus rate of migration. Consistent with this explanation, the horizontal position of homing Atlantic salmon in a Norwegian fjord was related to wind direction, presumably because the fish followed brackish water that contained olfactory cues that were spread across the fjord by wind (Davidsen et al., 2013). A stronger olfactory cue may also accelerate reproductive maturation by triggering an increase in circulating reproductive hormones through a neuroendocrine pathway as evidenced by elevated levels of gonadotropin-releasing hormone $(\mathrm{sGnRH})$ in the olfactory bulb of homing chum salmon (Oncorhynchus keta) in an estuary (Ueda, 2011), which can lead to increases in steroid hormones that fuel gamete development (Ueda and Yamauchi, 1995). Interestingly, more reproductively mature sockeye salmon (as evidenced by higher concentrations of circulating reproductive hormones) migrated faster from coastal waters into the Fraser River than less reproductively mature individuals (Crossin et al., 2007, 2009; Cooke et al., 2008a). In our study, PC2, which represented reproductive maturity, was present in all top-ranked 'physiological' models for the central SoG region, suggesting it may be an important variable. Model estimates for 
PC2 indicated that more reproductively mature fish migrated faster into the river, which is consistent with findings from previous studies. However, we cannot rule out the possibility of no effect of PC2 on sockeye salmon migration rate based on coverage of the confidence intervals for this variable. Additional field studies that examine endocrine and neural responses along varying migration distances (or olfactory gradients) [see examples from (Ueda, 2011)] are needed to gain a better understanding of how homing salmon respond to olfactory cues in estuarine environments. Despite these additional studies, the challenge remains for linking neuroendocrine responses to the behaviour of wild migrating fish.

Converse to the northern SoG region, stronger northwesterly winds were associated with faster migration rates for sockeye salmon migrating in the central SoG region (i.e., from the NSOG array to the Fraser River). We offer two possible explanations for this association. First, once sockeye salmon have adequately located the Fraser River plume, energy conservation may become more important before embarking on the energetically demanding up-river migration in warmer waters (Patterson et al., 2007; Farrell et al., 2008). Therefore, they take advantage of wind-generated currents in the direction of the Fraser River to aid in movements as an energy-saving strategy. An alternative explanation is that stronger northwesterly winds could have forced higher salinity surface waters exiting the Discovery Passage southeastward along the SoG exposing sockeye salmon to higher salinities. As sockeye salmon are progressively becoming more acclimated for fresh water while migrating through the SoG (Shrimpton et al., 2005), they may have attempted to avoid higher salinity water by migrating faster towards fresh water. Supporting our latter explanation, homing sockeye salmon that were captured in marine waters and were experimentally acclimated to fresh water migrated faster into the Fraser River after release into the estuary compared to fish held in either saltwater or iso-osmotic water (Hinch et al., 2009). Avoidance of higher salinity water by sockeye salmon that are becoming fresh water acclimated could also aid in explaining our finding that higher salinity in the northern SoG region was associated with faster migration rates.

Interestingly, an earlier study found that sockeye salmon experiencing lower salinity in coastal waters along the southwest side of Vancouver Island (e.g. Juan de Fuca Strait) migrated faster into the Fraser River (Thomson and Hourston, 2011). Sockeye salmon physiological state (including osmoregulatory state) has been shown to differ from fish sampled while using either Juan de Fuca Strait or Discovery Passage as migratory routes, which was attributed to previous environmental experience (Evans et al., 2011). Therefore, we attribute the opposite responses to salinity between Thomson and Hourston (2011), in which stocks had entered the SoG via Juan de Fuca Strait, and our study, in which stocks had entered the SoG via Discovery Passage, to differences in prior environmental experience and different physiological states of sockeye salmon from the two distinct migratory routes. Further studies that experimentally manipulate salinity levels and test for physiological and behavioural responses [as in (Cooperman et al., 2010)] are needed to gain a better understanding of how the osmoregulatory state plays a role in the migratory behaviour of homing anadromous salmonids.

Our results indicated that the association of glucose and migration rate varied by stock in the northern SoG region. Glucose is mobilized in response to exercise and physiological stress, and a previous study on homing sockeye salmon sampled in coastal marine waters found glucose was related to river entry timing (Crossin et al., 2007). Our finding indicates there were stock-specific responses to exercise or physiological stress induced by the capture and tagging event. However, glucose, stock and the interaction between glucose and stock were not present in all top-ranked models, which suggests uncertainty as to their overall importance to migration rate in the northern SoG region.

Tissue biopsy is a technique commonly used to examine the physiological mechanisms underlying migration of Pacific salmonids (Cooke et al., 2008b) and has been previously validated in the field (Cooke et al., 2005). However, results from our study indicated that sockeye salmon from the 'biopsy' treatment migrated slower than the 'control' group in the northern SoG region, but there was no effect of treatment on migration rate in the central SoG region. Physiological recovery from a stressor has been shown to occur over a 24-to 48-h period in homing anadromous salmonids (Donaldson et al., 2010), which corresponds to the approximate mean amount of travel time from the release site to the NSOG array ( 2.4 days $)$ and suggests that sockeye salmon had recovered from the 'biopsy' treatment by the time they were migrating in the central SoG region. Overall, the effect size of tissue biopsy on migration rate in our study was very small as 'biopsied' fish travelled $\sim 6.5 \mathrm{~km}$ per day slower than 'control' fish, which represents $\sim 16 \%$ of the average migration rate in the northern SoG region. Furthermore, the effects of tissue biopsy are likely insignificant compared to the larger effects associated with the 
capture event. More importantly, our finding that tissue biopsy (or the additional handling time associated with tissue sampling) can have an effect on migration rate highlights the importance of incorporating control treatments into studies using tissue biopsy, especially when examining behaviour immediately after release. Researchers could also consider incorporating variable handling times into study designs to test specifically for an effect of handling time.

This study presented details on migration routes, rate and timing of homing sockeye salmon in the SoG, and further provided empirical evidence of how environmental characteristics are associated with migration timing and rate. These results are of particular importance for Fraser River sockeye salmon, which are in need of a better biological understanding owing to recent variability in returning numbers of spawners (Cohen, 2012). Specifically, information on movement patterns (and the variables influencing them) is useful for forming management strategies of commercial fisheries, which target Fraser River sockeye salmon during this phase of the homing migration. In addition, our results showing an effect of wind and a short-term effect of tissue biopsy on estuarine migration rate are broadly applicable to those studying biological processes influencing anadromous salmonids during their marine homing migration.

\section{ACKNOWLEDGEMENTS}

This study was funded through the Ocean Tracking Network (OTN) Canada via a Natural Sciences and Engineering Research Council (NSERC) and Canada Foundation for Innovation grant to Dalhousie University. Hinch and Cooke are further supported by NSERC DG program, and Cooke is supported by the Canada Research Chairs program. Furey is supported by a Vanier Graduate Scholarship through NSERC. We thank two anonymous reviewers for their comments and suggestions. Special thanks to Jayme Hills, Charlotte Whitney, Jenn Burt, Andrea Haas, Doug Braun and members of the DFO Environmental Watch crew and the Pacific Salmon Conservation and Physiology laboratory for laboratory and field assistance. Additional thanks to Captain Michael and Penny Griswold.

\section{REFERENCES}

Aprahamian, M.W., Jones, G.O. and Gough, P.J. (1998) Movement of adult Atlantic salmon in the Usk estuary. Wales. J. Fish Biol. 53:221-225.
Barton, K. (2013) MuMIN: Multimodel Inference. R package version 1.9.0. http://CRAN.R-project.org/package=MuMIn. Accessed 5 November, 2014.

Beacham, T.D., Lapointe, M., Candy, J.R. et al. (2004) Stock identification of Fraser River sockeye salmon using microsatellites and major histocompatibility complex variation. Trans. Am. Fish. Soc. 133:1117-1137.

Burnham, K.P. and Anderson, D.R. (2002) Model Selection and Multimodel Inference: A Practical Information-Theoretical Approach. New York, NY: Springer-Verlag.

Clark, T.D., Donaldson, M.R., Drenner, S.M., Hinch, S.G., Patterson, D.A., Hills, J.A., Ives, V., Carter, J.J., Cooke, S.J. and Farrell, A.P. (2011) The efficacy of field techniques for obtaining and storing blood samples from fishes. J. Fish Biol., 79.

Cohen, B. (2012) Commision of Inquiry Into the Decline of Sockeye Salmon in the Fraser River (Canada): Final Report. Ottawa: Minister of Public Works and Government Services Canada.

Cooke, S.J., Hinch, S.G., Farrell, A.P. et al. (2004) Abnormal migration timing and high en route mortality of sockeye salmon in the Fraser River, British Columbia. Fisheries 29:22-33.

Cooke, S.J., Crossin, G.T., Patterson, D.A. et al. (2005) Coupling non-invasive physiological assessments with telemetry to understand inter-individual variation in behaviour and survivorship of sockeye salmon: development and validation of a technique. J. Fish Biol. 67:1342-1358.

Cooke, S.J., Hinch, S.G., Crossin, G.T. et al. (2006) Mechanistic basis of individual mortality in Pacific salmon during spawning migrations. Ecology 87:1575-1586.

Cooke, S.J., Hinch, S.G., Crossin, G.T. et al. (2008a) Physiological correlates of coastal arrival and river entry timing in late summer Fraser River sockeye salmon (Oncorhynchus nerka). Behav. Ecol. 19:747-758.

Cooke, S.J., Hinch, S.G., Farrell, A.P. et al. (2008b) Developing a mechanistic understanding of fish migrations by linking telemetry with physiology, behavior, genomics and experimental biology: an interdisciplinary case study on adult Fraser River sockeye salmon. Fisheries 33:321-338.

Cooperman, M.S., Hinch, S.G., Crossin, G.T., Cooke, S.J., Patterson, D.A., Olsson, I., Lotto, A.G., Welch, D.W., Shrimpton, J.M., Van Der Kraak, G. and Farrell, A.P. (2010) Effects of experimental manipulation of salinity and maturation status on the physiological condition and mortality of homing adult sockeye salmon held in a laboratory. Physiol. Biochem. Zool., 83:459-472.

Crossin, G.T. and Hinch, S.G. (2005) A nonlethal, rapid method for assessing the somatic energy content of migrating adult pacific salmon. Trans. Am. Fish. Soc., 134: 184-191.

Crossin, G.T., Hinch, S.G., Cooke, S.J. et al. (2007) Behaviour and physiology of sockeye salmon homing through coastal waters to a natal river. Mar. Biol. 152:905-918.

Crossin, G.T., Hinch, S.G., Cooke, S.J. et al. (2009) Mechanisms influencing the timing and success of reproductive migration in a capital breeding semelparous fish species, the sockeye salmon. Physiol. Biochem. Zool. 82:635652.

Davidsen, J.G., Rikardsen, A.H., Thorstad, E.B. et al. (2013) Homing behaviour of Atlantic salmon (Salmo salar) during final phase of marine migration and river entry. Can. J. Fish Aquat. Sci. 70:794-802. 
Dittman, A.H. and Quinn, T.P. (1996) Homing in Pacific salmon: mechanisms and ecological basis. J. Exp. Biol. 199:83-91.

Donaldson, M.R., Clark, T.D., Hinch, S.G. et al. (2010) Physiological responses of free-swimming adult coho salmon to simulated predator and fisheries encounters. Physiol. Biochem. Zool. 83:973-983.

Donaldson, M.R., Hinch, S.G., Raby, G.D., Patterson, D.A., Farrell, A.P. and Cooke, S.J. (2012) Population-specific consequences of fisheries-related stressors on adult sockeye salmon. Physiol. Biochem. Zool., 85:729-739.

Døving, K.B. and Stabell, O.B. (2003) Trails in open water: sensory cues in salmon migration. In Sensory Processing in Aquatic Environments. S.P. Collin, N.J. Marshall (eds) New York: Springer-Verlag, pp. 39-52.

Døving, K.B., Westerberg, H. and Johnsen, P.B. (1985) Role of olfaction in the behavioral and neuronal responses of Altantic salmon, Salmo salar, to hydrographic stratification. Can. J. Fish Aquat. Sci. 42:1658-1667.

Drenner, S.M., Clark, T.D., Whitney, C.K., Martins, E.G., Cooke, S.J. and Hinch, S.G. (2012) A synthesis of tagging studies examining the behaviour and survival of anadromous salmonids in marine environments. PLoS ONE, 7:e31311. doi:31310.31371/journal.pone.0031311.

Evans, T.G., Hammill, E., Kaukinen, K. et al. (2011) Transcriptomics of environmental acclimatization and survival in wild adult Pacific sockeye salmon (Oncorhynchus nerka) during spawning migration. Mol. Ecol. 20:4472-4489.

Farrell, A.P., Gallaugher, P.E., Fraser, J. et al. (2001) Successful recovery of the physiological status of coho salmon on board a commercial gillnet vessel by means of a newly designed revival box. Can. J. Fish Aquat. Sci. 58:1932-1946.

Farrell, A.P., Hinch, S.G., Cooke, S.J. et al. (2008) Pacific salmon in hot water: applying metabolic scope models and biotelemetry to predict the success of spawning migrations. Physiol. Biochem. Zool. 81:697-708.

Field, A., Miles, J. and Field, Z. (2012) Discovering Statistics using R. London: SAGE Publications Ltd.

Gelman, A. (2008) Scaling regression inputs by dividing by two standard deviations. Stat. Med. 27:2865-2873.

Groot, C. and Margolis, L. (1991) Pacific Salmon Life Histories. Vancouver, BC: UBC Press.

Hansen, L.P. and Jonsson, B. (1991) Evidence of a genetic component in the seasonal return pattern of Atlantic salmon, Salmo salar L.. J. Fish Biol. 38:251-258.

Hasler, A.D. and Scholz, A.T. (1983) Olfactory imprinting and homing in salmon. In Zoophysiology. B. Heinrich, K. Johansen, H. Langer, G. Neuweiler, D.J. Randall (eds) New York: Springer-Verlag, pp. 3-131.

Healey, M.C. (2000) Pacific salmon migrations in a dynamic ocean. In Fisheries Oceanography: An Integrative Approach to Fisheries Ecology and Management. P.J. Harrison, T.R. Parsons (eds) Oxford: Blackwell Science, pp. 29-54.

Heupel, M.R., Semmens, J.M. and Hobday, A.J. (2006) Automated acoustic tracking of aquatic animals: scales, design and deployment of listening station arrays. Mar. Freshwat. Res. 57:1-13.

Hinch, S.G., Cooke, S.J., Healey, M.C. and Farrell, A.P. (2006) Behavioral physiology of fish migrations: salmon as a model approach. In Fish Physiology, Volume 24: Behaviour and Physiology of Fish. K. Sloman, S. Balshine, R. Wilson (eds) San Diego: Elsevier, pp. 239-295.
Hinch, S.G. (2009) Overview and synthesis: early migration and premature mortality in Fraser River Late-run sockeye salmon. In: Conference on early migration and premature mortality in Fraser River late-run sockeye salmon: proceedings. S.G. Hinch \& J. Gardner (eds) Vancouver, BC: Pacific Fisheries Resource Conservation Council. pp. 8-14.

Hinch, S.G., Cooke, S.J., Farrell, A.P., Miller, K.M., Lapointe, M. and Patterson, D.A. (2012) Dead fish swimming: a review of research on the early migration and high premature mortality in adult Fraser River sockeye salmon Oncorhynchus nerka. J. Fish Biol. 81:576-599.

Hodgson, S., Quinn, T.P., Hilborn, R., Francis, R.C. and Rogers, D.E. (2006) Marine and freshwater climatic factors affecting interannual variation in the timing of return migration to fresh water of sockeye salmon (Oncorhynchus nerka). Fish Oceanogr. 15:1-24.

Høgåsen, H.R. (1998) Physiological Changes Associated with the Diadromous Migration of Salmonids. Ottawa: NRC Research Press.

Jonsson, B. and Jonsson, N. (2009) A review of the likely effects of climate change on anadromous Atlantic salmon Salmo salar and brown trout Salmo trutta, with particular reference to water temperature and flow. J. Fish Biol. 75:2381-2447.

Jonsson, B., Jonsson, N. and Hansen, L.P. (2007) Factors affecting river entry of adult Atlantic salmon in a small river. J. Fish Biol. 71:943-956.

Keefer, M.L. and Caudill, C.C. (2014) Homing and straying by anadromous salmonids: a review of mechanisms and rates. Rev. Fish Biol. Fish 24:333-368.

Levy, D.A. and Cadenhead, A.D. (1995) Selective tidal stream transport of adult sockeye salmon (Oncorhynchus nerka) in the Fraser-River estuary. Can. J. Fish Aquat. Sci. 52:1-12.

Madison, D.M., Horrall, R.M., Hasler, A.D. and Stasko, A.B. (1972) Migratory movements of adult sockeye salmon (Oncorhynchus nerka) in coastal British Columbia as revealed by ultrasonic tracking. J. Fish. Res. Board Can. 29:10251033.

Patterson, D.A., Macdonald, J.S., Skibo, K.M., Barnes, D., Gethriel, I. and Hills, J. (2007) Reconstructing the summer thermal history for the lower Fraser River, 1941 to 2006, and implications for adult sockeye salmon (Oncorhynchus nerka) spawning migration. Can. Tech. Rep. Fish. Aquat. Sci. $2724: 43$

Quinn, T.P. (1988) Estimated swimming speeds of migrating adult sockeye salmon. Can. J. Zool. 66:2160-2163.

Quinn, T.P. and Dittman, A.H. (1990) Pacific salmon migrations and homing: mechanisms and adaptive significance. Trends Ecol. Evol. 5:174-177.

Quinn, T.P., terHart, B.A. and Groot, C. (1989) Migratory orientation and vertical movements of homing adult sockeye salmon, Oncorhynchus nerka, in coastal waters. Anim. Behav. 37:587-599.

R Core Development Team (2012) R: A Language and Environment for Statistical Computing. Vienna, Austria: R foundation for statistical computing.

Schielzeth, H. (2010) Simple means to improve the interpretability of regression coefficients. Methods Ecol. Evol. $1: 103-113$.

Shrimpton, J.M., Patterson, D.A., Richards, J.G. et al. (2005) Ionoregulatory changes in different populations of maturing sockeye salmon Oncorhynchus nerka during ocean and river migration. J. Exp. Biol. 208:4069-4078. 
Smith, I.P. and Smith, G.W. (1997) Tidal and diel timing of river entry by adult Atlantic salmon returning to the Aberdeenshire Dee, Scotland. J. Fish Biol. 50:463-474.

Stasko, A.B. (1975) Progress of migrating Atlantic salmon (Salmo salar) along an estuary, observed by ultrasonic tracking. J. Fish Biol. 7:329-338.

Stasko, A.B., Horrall, R.M. and Hasler, A.D. (1976) Coastal movements of adult Fraser River sockeye salmon (Oncorhynchus nerka) observed by ultrasonic tracking. Trans. Am. Fish. Soc. 105:64-71.

Taylor, E.B. (1991) A review of local adaptation in Salmonidae, with particular reference to Pacific and Atlantic salmon. Aquaculture 98:185-207.

Thomson, R.E. (1981) Oceanography of the British Columbia coast. Can. Spec. Pub. Fish. Aquat. Sci. 56:251.

Thomson, R.E. (1994) Physical oceanography of the Stait of Georgia-Puget Sound-Juan de Fuca Strait System. Can. Tech. Rep. Fish. Aquat. Sci. 1948:36-101.

Thomson, R.E. and Hourston, R.A.S. (2011) A matter of timing: the role of ocean conditions in the initiation of spawning migration by late-run Fraser River sockeye salmon (Oncorhynchus nerka). Fish Oceanogr. 20:47-65.

Thorstad, E.B., Whoriskye, F., Rikardsen, A.H. and Aarestrup, K. (2010) Aquatic nomads: the life and migrations of the Atlantic salmon. In Atlantic Salmon Ecology. $\varnothing$. Aas, S. Einum, A. Klemetsen, J. Skurdal (eds) Wiley-Blackwell: Oxford, UK, pp. 1-23.

Ueda, H. (2011) Physiological mechanism of homing migration in Pacific salmon from behavioural to molecular biological approaches. Gen. Comp. Endocrinol. 170:222-232.
Ueda, H. and Yamauchi, K. (1995) Biochemistry of fish migrations. In Biochemistry of Molecular Biology of Fishes. P.W. Hochachka, T.P. Mommsen (eds) Amsterdam: Elsevier, pp. 265-279.

Venables, W.N. and Ripley, B.D. (2002) Modern Applied Statistics With S, 4th edn. New York: Springer.

Welch, D.W., Melnychuk, M.C., Rechisky, E.R. et al. (2009) Freshwater and marine migration and survival of endangered Cultus Lake sockeye salmon (Oncorhynchus nerka) smolts using POST, a large-scale acoustic telemetry array. Can. J. Fish Aquat. Sci. 66:736-750.

Wilson, S.M., Hinch, S.G., Drenner, S.M. et al. (2014) Coastal marine and in-river migraiton behaviour of adult sockeye salmon en route to spawning grounds. Mar. Ecol. Prog. Ser. 496:71-84.

Zuur, A.F., Ieno, E.N., Walker, N.J., Saveliev, A.A. and Smith, G.M. (2009) Mixed Effects Models and Extensions in Ecology with R. New York: Springer.

Zuur, A.F., Ieno, E.N. and Elphick, C.S. (2010) A protocol for data exploration to avoid common statistical problems. Methods Ecol. Evol. 1:3-14.

\section{SUPPORTING INFORMATION}

Additional Supporting Information may be found in the online version of this article:

Table S1. Output of the principle component analysis (PCA) including all eight blood variables. 